\title{
Evaluation of Eco-environmental Sensitivity in Xilingol Grassland
}

\author{
Meili $^{1}$, Yinshan ${ }^{1,2, *}$, Duwala ${ }^{3}$, Yuhai Bao ${ }^{1,2}$, Yushan $^{2}$ \\ ${ }^{1}$ College of Geographical Sciences, Inner Mongolia Normal University, Hohhot 010022, China; \\ ${ }^{2}$ Remote Sensing and Information Key Laboratory, Inner Mongolia Normal University, Hohhot 010022 , \\ China; \\ ${ }^{3}$ Inner Mongolia Ecological and Agricultural Meteorological Center, Hohhot 010051, China
}

\section{锡林郭勒草原生态环境敏感性评价}

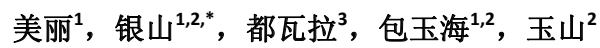 \\ ${ }^{1}$ 内蒙古师范大学 地理科学学院, 内蒙古呼和浩特 010022; \\ ${ }^{2}$ 内蒙古师范大学 内蒙古自治区遥感与地理信息重点实验室, 内蒙古呼和浩特 010022; \\ ${ }^{3}$ 内蒙古自治区生态与农业气象中心，内蒙古呼和浩特 010051;
}

\begin{abstract}
This paper selected the soil erosion, land desertization, bio-inhabitation as sensitive factor to research eco-environmental sensitivity spatial distribution characteristics of the Xilingol Grassland. (1)slight sensitivity is the main level of soil erosion sensitivity, which mainly distributes in the flat terrain of the plain area. Moderately sensitive area is distributed in mountainous and hilly areas.(2)In-sensitive and slight sensitive areas of desertification accounted for $0.004 \%$ and $3.186 \%$ of the total area, respectively, and the proportion of moderately sensitive area was $46.533 \%$, and highly sensitive area mainly distributed in the Hunshandake sandy land, where vegetation relatively sparse, and sand is the main soil type, and the sandstorm weather often happened. Sonid right and Sonid left banner is extreme sensitive area.(3)Bio-inhabitation sensitive level has a downward trend from southeast to northwest, highly sensitive areas distributed in the mountainous areas with high vegetation coverage and abundant rainfall. (4)Eco-environmental sensitive index is between 1.50935-5.57577 in Xilingol grassland, where the main sensitivity type is slight sensitivity,
\end{abstract}

*通讯作者：银山, yinshan@imnu.edu.cn. moderately sensitive areas distributed in Sonid right banner, Sonid left banner, Boarder Yellow banner, Abagaqi, west ujimqin and Xilinhot.

Keywords: Eco-environmental sensitivity; Soil erosion;Land desertization; Bio-inhabitation;

摘要

本文选取土壤侵蚀、土地沙漠化、生境 3 个敏 感性因子针对锡林郭勒草原生态敏感性空间 分布特征进行研究。(1)土壤侵蚀敏感性以轻度 敏感为主, 分布在地形平缓的平原区。中度敏 感区分布在低山丘陵区。(2)土地沙漠化的不敏 感、轻度敏感区占总面积的 $0.004 \%$ 和 $3.186 \%$, 中度敏感区比例为 $46.533 \%$, 高度敏感区在植 被相对稀疏、沙质土壤为主、风沙天气较多的 浑善达克沙地区域。极敏感区在苏尼特右旗和 苏尼特左旗。(3)生境敏感性等级自东南向西北 呈下降趋势, 高度敏感区在植被覆盖度高, 降 雨丰富的山地区域。(4)锡林郭勒草原的生态环 境敏感性指数在 1.50935-5.57577 之间, 锡林 郭勒草原以轻度敏感为主, 中度敏感区主要分 布在苏尼特左旗、苏尼特右旗、镶黄旗、阿巴 嘎旗、西乌珠穆沈旗和锡林浩特市。

关键词: 生态环境敏感性; 土壤侵蚀; 土地沙 漠化; 生境;

生态环境敏感性是指生态系统受人类活 动活动影响的敏感程度, 用来反映产生生态失 


\section{Risk Analysis and Crisis Response in Big Data Era (RAC-16)}

衡与生态环境问题的可能性大小 ${ }^{[1]}$ 。生态环境 敏感性评价中敏感性高的区域, 容易产生环境 问题, 所以是生态环境保护和恢复建设的重点 ${ }^{[2]}$ 。草原是我国国土和陆地生态系统的主体 ${ }^{[3]}$, 锡林郭勒草原含浑善达克沙地, 是我国温带典 型草原核心分布区 ${ }^{[4]}$ 。也是我国典型的生态环 境脆弱和敏感地区, 土壤侵蚀、土地沙漠化等 问题严重 ${ }^{[5]}$, 对草原地区生态环境造成严重损 失, 因此研究草原地区的生态环境敏感性区 域, 对草原的生态环境保护与建设具有重要意 义。

\section{1 研究方法}

\section{1 研究区}

锡林郭勒盟地处内蒙古自治区的中部。地 处东经 $115^{\circ} 13^{\prime}-117^{\circ} 06^{\prime}$ 、北纬 $43^{\circ} 02^{\prime}-44^{\circ} 52^{\prime}$ 。 属于大陆性气候, 年平均气温 $0-3^{\circ} \mathrm{C}$, 年均降 雨量 $295 \mathrm{~mm}$ 。植被类型以典型草原为主。

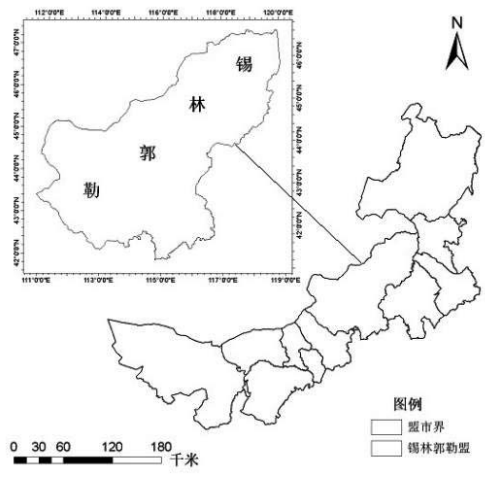

图 1.研究区示意图

Fig.1 The study area

\section{2 数据来源与处理}

植被数据: 本文选取 2000-2015 年的每年 4-10 月的空间分辨率为 $250 \mathrm{~m}$, 时间分辨率为 $16 \mathrm{~d}$ 的 MODIS13Q1 植被指数产品, 首先利用 ENVI5.1 软件进行 Albers Conical Equal Area 投影转换, 然后进行最大值合成, 再运用均值 法获取研究区的年平均 NDVI 值数据。

气象数据: 中国气象科学共享服务网下载 获取 2000-2010 年的月降雨量、月蒸发量、日 风速数据, 根据气象站点的经纬度信息对各站 点数据进行处理后在 ArcGIS 的 Spatial Analyst Tools 工具 Kriging 空间插值。

高程数据: 从(http://srtm.csi.cgiar.org/S
ELECTION/inputCoord.asp)网下载获取 DEM 数据, 从中提取坡度、坡长。

土壤质地: 从中国 1:100 万土壤属性数据 库提取, 土壤属性包括粗砂、粉砂、细沙、粘 粒、有机质和土壤类型。

\section{3 土壤侵蚀敏感性评价方法}

按照环保总局颁布的《生态功能区划暂行 规程》附件 $\mathrm{C}^{[6]}$ 中的土壤侵蚀敏感性评价选择 指标, 降雨侵蚀力和地形起伏度采用刘会军 ${ }^{[7]}$ 计算方法, 土壤可蚀性因子的计算采取陈学 华, 周建中等 ${ }^{[8]}$ 提出的计算为准。分别对单因 子敏感性划分五个等级, 然后利用公式在 ArcGIS软件的Spatial Analyst Tools工具进行 空间叠加, 公式如下:

$$
S S_{i}=\sqrt[4]{R_{i} \cdot K_{i} \cdot L S_{i} \cdot C_{i}}
$$

式中: $\mathrm{SS}_{\mathrm{i}}$ 为 $\mathrm{i}$ 空间单元土壤侵蚀敏感性指数; 评价因子包括降雨侵蚀力 $\left(\mathrm{R}_{\mathrm{i}}\right)$ 、土壤可蚀性 $\left(\mathrm{K}_{\mathrm{i}}\right)$ 、地形起伏度 $\left(\mathrm{LS}_{\mathrm{i}}\right)$ 、地表植被覆盖度 $\left(\mathrm{C}_{\mathrm{i}}\right)$ 。

\section{4 土地沙漠化敏感性评价方法}

按照环保总局颁布的《生态功能区划暂行 规程》附件 $\mathrm{C}^{[6]}$ 的土地沙漠化敏感性评价选取 指标, 本文湿润指数采用陈晓琴 ${ }^{[9]}$ 多年平均降 水量和蒸发量的比值, 起沙风天数参照张国平 [10]等提出的统计 11-5 月份中日均风速大于 6 $\mathrm{m} / \mathrm{s}$ 的天数。起沙风天数和植被覆盖度的敏感 性分类以刘军会 ${ }^{[7]}$ 等为参照。分别对单因子敏 感性划分五个等级, 然后利用公式在ArcGIS 软件的Spatial Analyst Tools工具进行空间叠 加, 公式如下:

$$
D S_{j}=\sqrt[4]{\prod_{i=1}^{4} D_{i}}
$$

式中: $D_{\mathrm{j}}$ 为 $\mathrm{j}$ 空间单元沙漠化敏感性指数; $D_{i}$ 为 $\mathrm{i}$ 评价因子敏感性等级值。

\section{5 生态环境敏感性综合评价方法}

单因子的敏感性仅反映了某一因子对生 态环境的作用程度 ${ }^{[11]}$, 评价因子权重采用变异 系数法确定, 用各因子变异系数占因子变异系 数和的比重来确定各因子的权重 ${ }^{[12]}$ 。利用 ArcGIS软件进行空间叠加, 公式如下:

$$
E S_{i}=\sum_{i=1}^{3} W_{i} F_{i}
$$


Risk Analysis and Crisis Response in Big Data Era (RAC-16)

式中: ${E S_{i}}_{i}$ 为综合土地生态敏感性指数; $F_{i}$ 为 $i$ 评价因子指数。 $\mathrm{W}_{\mathrm{i}}$ 分别是土地沙漠化敏感性因 子权重为 0.26 , 土壤侵蚀敏感性、生境敏感性 因子权重分别为 0.3 和 0.44 。

\section{2 结果与分析}

\section{1 土壤侵蚀敏感性评价}

土壤侵蚀敏感性评价选择降雨侵蚀力、土 壤可蚀性、地形起伏度以及植被覆盖度 4 个指 标的分级标准如表 1 所示:

表 1. 土壤侵蚀敏感性的评价指标及分级标准

Tab.1 Index and classification standard of soil erosion sensitivity evaluation

\begin{tabular}{|c|c|c|c|c|c|c|}
\hline 分级 & $\begin{array}{l}\text { 降雨侵蚀 } \\
\text { 力 }\end{array}$ & $\begin{array}{l}\text { 土壤可蚀性因 } \\
\text { 子 }\end{array}$ & $\begin{array}{l}\text { 地形起伏度 } \\
(\mathrm{m})\end{array}$ & $\begin{array}{l}\text { 植被覆 盖 } \\
\text { 度 }\end{array}$ & 分级标准 & 分级赋值 \\
\hline 不敏感 & $<25$ & $<0.2$ & $0-20$ & $\geq 80 \%$ & $1.0-2.0$ & 1 \\
\hline 轻度敏感 & $25-100$ & $0.2-0.25$ & $21-50$ & $60-80 \%$ & $2.1-4.0$ & 3 \\
\hline 中度敏感 & $100-400$ & $0.25-0.3$ & $51-100$ & $40-60 \%$ & $4.1-6.0$ & 5 \\
\hline 高度敏感 & $400-600$ & $0.3-0.4$ & $101-300$ & $20-40 \%$ & $6.1-8.0$ & 7 \\
\hline 极敏感 & $>600$ & $>0.4$ & $>300$ & $\leq 20 \%$ & $>8.0$ & 9 \\
\hline
\end{tabular}
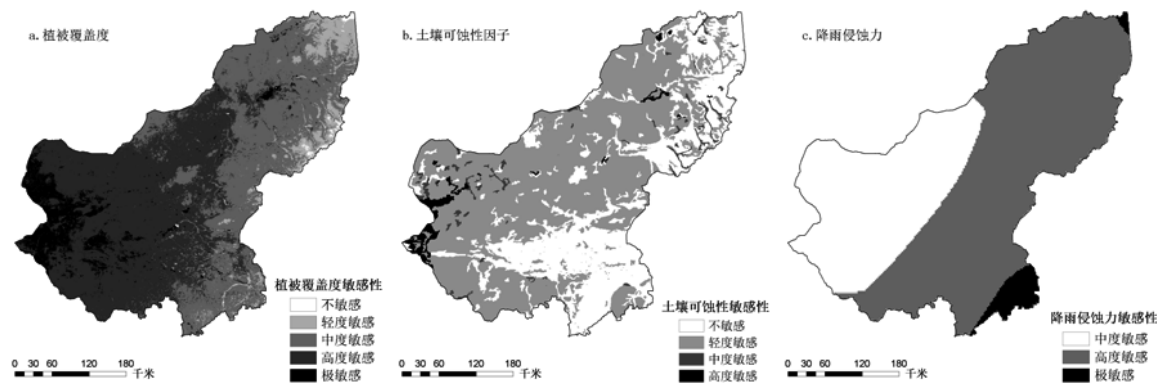

$\stackrel{0.3060 \quad 120}{2} \quad 100$

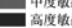

$\stackrel{-3000-120}{-1300}+*$

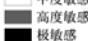
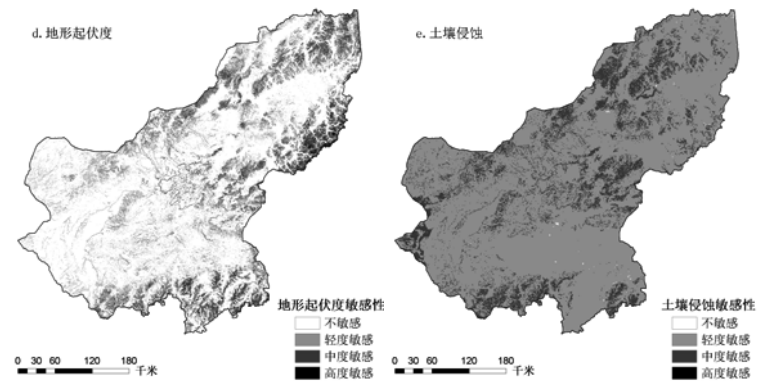

图 2.土壤侵蚀敏感性评价

Fig.2 Sensitivity evaluation of soil erosion

由图 2 可见, 植被覆盖度的极敏感区位于 植被覆盖度 $\leq 20 \%$ 的湖泊周边的盐碱地及西北 部, 高度敏感区在植被覆盖度 $20-40 \%$ 的西部,
植被覆盖度 $40-60 \%$ 的东部为中度敏感, 轻度 敏感区在东乌珠穆沈旗和西乌珠穆沈旗, 东南 部的森林地区为不敏感。土壤可蚀性因子 0.3 


\section{Risk Analysis and Crisis Response in Big Data Era (RAC-16)}

-0.4 的草甸盐土、淡棕铻土分布是高度敏感 区, 沼泽土分布区中度敏感, 轻度敏感区分布 在栗钙土、棕钙土、淡栗钙土。降雨侵蚀力的 中度敏感区分布在降水少的西北部, 高度敏感 区在年降雨量为 $400-600 \mathrm{~mm}$ 的中部, 极敏感 区在年降雨丰富的东部和南部。地形起伏度的 高度敏感区在地形起伏明显, 坡度较高的山地 地区, 这些地区是大兴安岭及阴山山脉向东西 延伸的余脉, 中度敏感区在坡度相对较低的丘 陵地区, 不敏感区在地形相对平缓的平原区。

从表 4 可以看出, 不敏感和高度敏感区分
布较少, 锡林郭勒盟的土壤侵蚀敏感性以轻度 敏感 $\left(167030.437 \mathrm{~km}^{2}\right)$ 为主, 占总面积的 $83.479 \%$, 轻度敏感区分布最广, 主要分布在 地形平缓的中部平原区。中度敏感区面积为 $32891.119 \mathrm{~km}^{2}$, 比例为 $16.438 \%$, 主要分布在 降雨侵蚀力较大, 地势起伏明显, 坡度较高的 山地丘陵区。

\section{2 土地沙漠化敏感性评价}

土地沙漠化敏感性评价选取湿润指数、冬 春季 $\geq 6 \mathrm{~m} / \mathrm{s}$ 起沙风天数、土壤质地、植被覆盖 度 4 个指标的分级标准如表 2 所示:

表 2.土地沙漠化敏感性评价指标分级标准

Tab.2 Index and classification standard of land desertization sensitivity evaluation

\begin{tabular}{l|llllll}
\hline 分级 & 湿润指数 & $\begin{array}{l}\text { 冬春季 } \geq 6 \mathrm{~m} / \mathrm{s} \\
\text { 起沙风天数 }\end{array}$ & 土壤质地 & 植被覆盖度 & 分级标准 & 分级赋值 \\
\hline 不敏感 & $>0.65$ & $\leq 5$ & 基岩 & $\geq 80 \%$ & $1.0-2.0$ & 1 \\
轻度敏感 & $0.5-0.65$ & $5-10$ & 黏质 & $60-80 \%$ & $2.1-4.0$ & 3 \\
中度敏感 & $0.2-0.5$ & $10-20$ & 砂质 & $40-60 \%$ & $4.1-6.0$ & 5 \\
高度敏感 & $0.05-0.2$ & $20-30$ & 壤质 & $20-40 \%$ & $6.1-8.0$ & 7 \\
极敏感 & $<0.05$ & $\geq 30$ & 沙质 & $\leq 20 \%$ & $>8.0$ & 9 \\
\hline
\end{tabular}

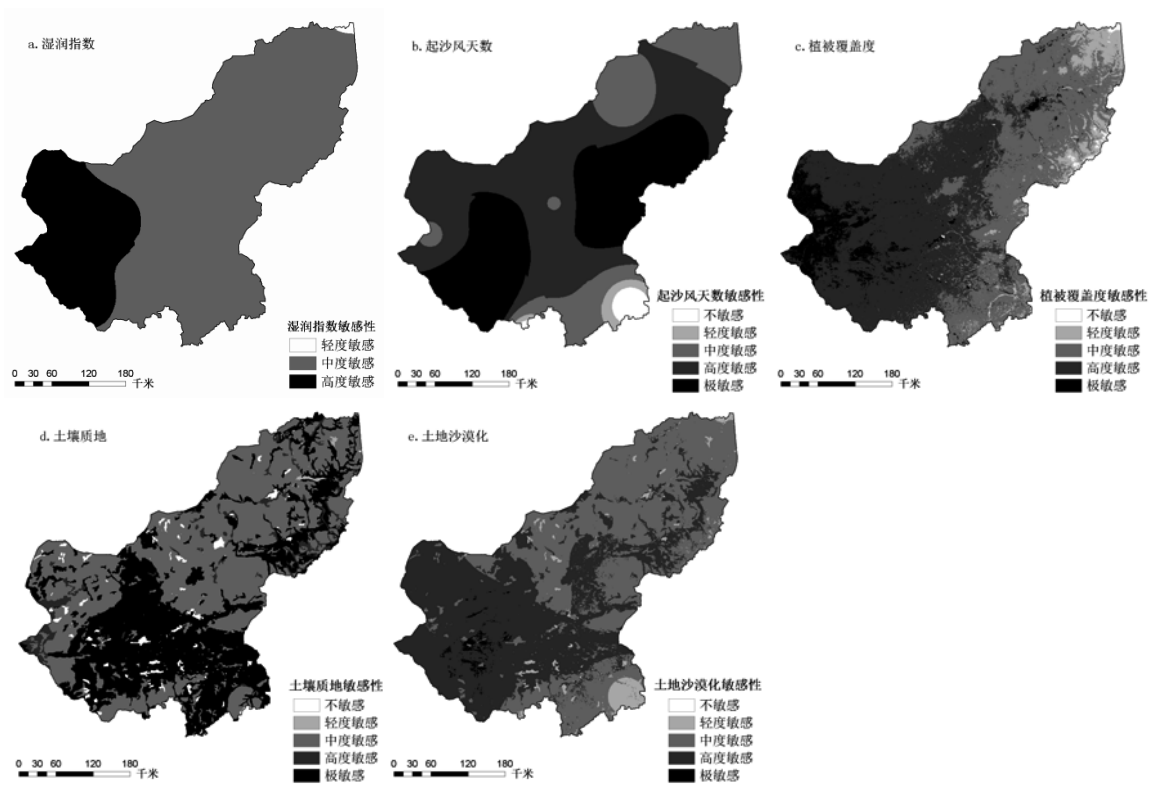

图 3.土地沙漠化敏感性评价

Fig.3 Sensitivity evaluation of land desertization 
Risk Analysis and Crisis Response in Big Data Era (RAC-16)

锡林郭勒草原的土地沙漠化敏感性指数 在 1.96799-8.45194 之间, 从图 3 看出, 沙漠 化敏感性指数较高区在沙地区域, 湖泊等地的 沙漠化敏感性指数较低。不敏感、轻度敏感区 分布零散, 不敏感区面积为 $7.984 \mathrm{~km}^{2}$, 占总面 积的 $0.004 \%$ (表 4)。轻度敏感区面积 6385.210 $\mathrm{km}^{2}$, 占总面积的 $3.186 \%$ 。中度敏感区分布在 锡林郭勒盟的气候相对湿润, 冬春季 $\geq 6 \mathrm{~m} / \mathrm{s}$ 起 沙风天数在 10-30 天内, 土壤质地为砂质, 植 被覆盖度较好的东部和西南部, 面积为 $93256.207 \mathrm{~km}^{2}$, 占总面积的 $46.533 \%$ 。高度敏
感区在锡林郭勒盟的植被相对稀疏、沙质土壤 为主、风沙天气较多并干燥的浑善达克沙地区 域, 面积为 $98798.107 \mathrm{~km}^{2}$, 占总面积的 $49.299 \%$ 。极敏感区在锡林郭勒盟的苏尼特右 旗和苏尼特左旗, 面积为 $1960.074 \mathrm{~km}^{2}$, 占总 面积的 $0.978 \%$ 。锡林郭勒草原的土地沙漠化 以高度敏感为主。

\section{3 生境敏感性评价}

参照刘军会 ${ }^{[7]}$ 对内蒙古的生态环境敏感 性评价中生境敏感性选取NDVI指数进行敏感 性分类, 如表 3 所示:

表 3.生境敏感性评价指标分级标准

Tab.3 Index and classification standard of bio-inhabitation sensitivity evaluation

\begin{tabular}{l|lllll}
\hline 分级 & 不敏感 & 轻度敏感 & 中度敏感 & 高度敏感 & 极敏感 \\
\hline NDVI 值 & $0-0.16$ & $0.16-0.38$ & $0.38-0.60$ & $0.60-0.83$ & $0.83-1.00$ \\
分级赋值 & 1 & 3 & 5 & 7 & 9 \\
\hline
\end{tabular}

从图 4 看出, 锡林郭勒盟植被类型为草原 植被, 锡林郭勒草原的生境敏感性等级自东南 向西北呈逐步下降趋势, 不敏感区在锡林郭勒 盟的西北部，占总面积的 $11.381 \%$ 。轻度敏感 区面积宽广, 占草原面积的 76.014\%(表 4),
中度敏感区在锡林郭勒盟的东部和南部, NDVI 指数在 0.38-0.6 之间, 占总面积的 $12.425 \%$ 。高度敏感区在锡林郭勒盟的植被覆 盖度高, 降水丰富的山地区域, 占总面积的 $0.179 \%$ 。生境敏感性以中度敏感为主。

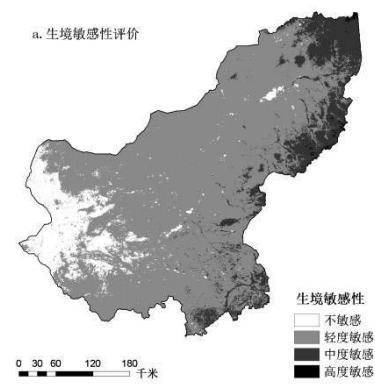

图 4. 生境敏感性评价 (a)

Fig.4 Sensitivity evaluation of bio-inhabitation

\section{4 生态环境敏感性综合评价}

锡林郭勒草原的生态环境敏感性指数在 1.50935-5.57577 之间(图 5)。从表 4 所知, 锡 林郭勒草原以轻度敏感为主, 面积为 $118069.383 \mathrm{~km}^{2}$, 占总面积的 $58.922 \%$, 主要分 布在锡林郭勒草原的东乌珠穆沁旗中部、阿巴 嘎旗东部、苏尼特旗西北部、正镶白旗、正蓝

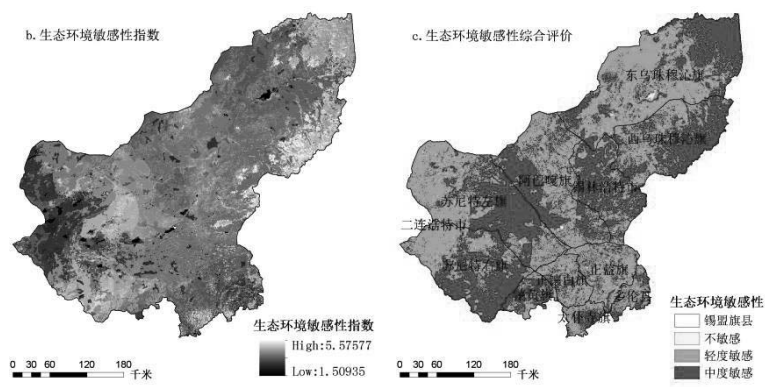

图 5. 生态环境敏感性综合评价 (b. c)

Fig.5 Sensitivity evaluation of eco-environmental

旗多伦县地区。中度敏感区所占面积为 $81990.560 \mathrm{~km}^{2}$, 比例为 $40.917 \%$, 主要集中分 布在苏尼特左旗、苏尼特右旗、镶黄旗、阿巴 嘎旗、西乌珠穆沈旗及锡林浩特市。这些区域 易受人类活动影响敏感性较高。不敏感区分布 在湖泊等地, 面积为 $320.936 \mathrm{~km}^{2}$, 占总面积 的 $0.160 \%$ 。 
Risk Analysis and Crisis Response in Big Data Era (RAC-16)

表 4.生态环境敏感性综合评价结果

Tab.4 Sensitivity evaluation of eco-environmental results

\begin{tabular}{c|cccccccc}
\hline \multirow{2}{*}{ 分级 } & \multicolumn{3}{|c}{ 土壤侵蚀敏感性 } & \multicolumn{2}{c}{ 沙漠化敏感性 } & \multicolumn{2}{c}{ 生境敏感性 } & \multicolumn{2}{c}{ 生态环境敏感性 } \\
\cline { 2 - 9 } & 面积 $(\mathrm{km} 2)$ & 比例 & 面积 $(\mathrm{km} 2)$ & 比例 & 面积 $\left(\mathrm{km}^{2}\right)$ & 比例 & 面积 $(\mathrm{km} 2)$ & 比例 \\
\hline 不敏感 & 162.674 & 0.081 & 7.984 & 0.004 & 22904.493 & 11.381 & 320.936 & 0.160 \\
轻度敏感 & 167030.437 & 83.479 & 6385.21 & 3.186 & 152973.776 & 76.014 & 118069.383 & 58.922 \\
中度敏感 & 32891.119 & 16.438 & 93256.207 & 46.533 & 25004.599 & 12.425 & 81990.560 & 40.917 \\
高度敏感 & 2.994 & 0.001 & 98798.107 & 49.299 & 360.518 & 0.179 & & \\
极敏感 & & & 1960.074 & 0.978 & & & & \\
\hline
\end{tabular}

3 结论

(1)锡林郭勒草原的土壤侵蚀敏感性以轻度敏 感为主, 占总面积的 $83.479 \%$, 轻度敏感区分 布在地形平缓的平原区。中度敏感区比例为 $16.438 \%$, 中度敏感区分布在山地丘陵区。高 度敏感区面积为 $2.994 \mathrm{~km}^{2}$ 。

(2)沙漠化敏感性指数较高分布在沙地区域, 湖 泊等地的沙漠化敏感性指数较低。不敏感、轻 度敏感区占总面积的 $0.004 \%$ 和 $3.186 \%$ 。中度 敏感区占总面积的 $46.533 \%$ 。高度敏感区分布 在植被相对稀疏、沙质、风沙天气较多的浑善 达克沙地区域, 占总面积的 $49.299 \%$ 。极敏感 区在锡林郭勒盟的苏尼特右旗和苏尼特左旗。 (3)锡林郭勒草原的生境敏感性等级自东南向 西北呈下降趋势, 不敏感区在锡林郭勒盟的西 北部, 轻度敏感区占草原面积的 $76.014 \%$, 中 度敏感区在锡林郭勒盟的东南部。高度敏感区 在锡林郭勒草原的植被覆盖度高, 降雨丰富的 山地区域, 占总面积的 $0.179 \%$ 。

(4)生态环境敏感性指数在 1.50935-5.57577 之 间, 锡林郭勒草原以轻度敏感为主, 中度敏感 区占总面积的 $0.160 \%$, 主要分布在苏尼特左 旗、苏尼特右旗、镶黄旗、阿巴嘎旗、西乌珠 穆沈旗和锡林浩特市。

\section{Acknowledgements}

This study was supported by Natural Science Foundationthe of Inner Mongolia Autonomous Region(No.2013ZD08), Inner Mongolia Normal University major project to cultivate special project (No.2013ZDPY04), National" Twelfth Five Year" Plan Project for Science and Technology Support(No.2013BAK05B01) and Natural Science Foundation of China
(No.41161060)。

\section{致谢}

本研究得到了资助项目: 内蒙古自然科学基金 (2013ZD08)、内蒙古师范大学科研基金重大培 育项目(2013ZDPY04)、国家“十二五”科技支撑 计划项目 (2013BAK05B01) 和国家自然科学 基金(41461102)共同资助。

\section{参考文献}

[1]李淑芳,马俊杰,唐升义,杨否等.基于 GIS 的宝鸡 市土地生态环境敏感性评价.水土保持学 报,2009,29(4):201-204.

[2]李东梅,吴晓青,于德永,高正文,吴钢等.云南省生 态环境敏感性评价.生态学报, 2008, 28(11): 523-527.

[3]X.H. Li, W.J. Wu, D.D Lv, C. H. Zhang.Research on Risk Assessment and Regionalization of Forest and Grassland Fires. Journal of Risk Analysis and Crisis Response, 2012,2(1):69-77.

[4]李彰俊,郝璐,李兴华.积雪覆盖度对沙尘暴影响 分析.中国沙漠,2008,28(2):338-343.

[5]马清霞,王星晨, 高志国等.锡林郭勒草原荒漠化 气候因素分析.北方环境,2011,23(12):31-34.

[6]中国科学院.生态功能区划暂行规程. http://www.Chinaenvironment.com.

[7]刘军会, 高吉喜, 马 苏, 王文杰, 邹长新等.内蒙古 生态环境敏感性综合评价.中国环境科 学,2015,35(2):591-598.

[8]陈学华,周建中,基于 GIS 和 RS 的四川省彭州市 土壤侵蚀敏感性评价. 山地学报, 2011, 29(6): 707-712.

[9]陈晓琴,张娟,王静慧,冯永盛,祁永发等.青海湖流 域土地沙漠化敏感性评价研究.群文天 
Risk Analysis and Crisis Response in Big Data Era (RAC-16)

地,2012(3):94-96

[10] 张国平,张增祥,刘纪远等.中国土壤风力侵蚀空 间格局及驱动因子分析. 地理学报, 2001, 56(2):

146-158.

[11] 李君轶,吴晋峰,薛亮,陈晓军等.基于 GIS 的陕西 省土地生态环境敏感性评价研究.干旱地区农 业研究,2007,25(4):20-29.

[12] 吴金华,李纪伟,朱鸿儒等,基于 ArcGIS 区统计 的延安市土地生态敏感性评价. 自然资源学 报,2011,26(7):1181-1186. 